\title{
UNAPREĐENJE PROCESA NABAVKE REPROMATERIJALA U KOMPANIJI „HUTCHINSON"
}

\section{IMPROVEMENT OF RAW MATERIAL PROCUREMENT PROCESS IN „HUTCHINSON"}

\author{
Radovan Petrović, Fakultet tehničkih nauka, Novi Sad
}

\section{Oblast - INŽENJERSKI MENADŽMENT}

Kratak sadržaj - Tema ovog rada jeste predstavljanje logističkih procesa u kompaniji „Hutchinson“, sa naglaskom na procesu nabavke repromaterijala. Cilj je da se na osnovu svega navedenog predlože mjere koje bi dovele do unapređenja poslovanja.

Kljucne reci: Nabavka, unapređenje, repromaterijal

Abstract - The topic of this paper is presentation of logistics processes at „Hutchinson" company, with an emphasis on the process of procurement of raw materials. The main goal, on the basis of all the above, are measures that would lead to business improvement.

Keywords: Procurement; Improvements; Raw materials

\section{UVOD}

Svako preduzeće koje se bavi proizvodnim djelatnostima, odnosno transformacijom predmeta rada sa ciljem povećanja njegove vrijednosti, mora posvetiti veliku pažnju sektoru logistike. Veliku ulogu u ostvarivanju ciljeva preduzeća, ima logistika nabavke, čija je osnovna svrha snabdjevanje preduzeća repromaterijalom. Lanac snabdjevanja obuhvata sve učesnike i procese od proizvođača sirovina do krajnjeg potrošača, ali se iz perspective operativnog upravljanja klasično razmatraju tri osnovne komponente: snabdjevanje (nabavka), skladištenje i distribucija.

\section{LOGISTIKA}

Logistika je veoma stara oblast poslovanja koja se usavršavala sa razvojem civilizacije. Najprije se vezuje za vojnu nauku. Vizantijski car Leontos (886. - 911.god. n.e.) je izjavio: „Logistika treba da naoruža vojsku srazmjerno potrebi za sredstvima zaštite i oružjem, da se pravovremeno brine o njenim potrebama na terenu i da pripremi svaku njenu akciju u ratnom pokretu".

Faze razvoja logistike:

- Do 1960. godine - Kapacitet proizvodnje maksimalno iskorišćen, logistika, kao posebna prvi put je uvedena 50-tih godina, po cijeloj kompaniji;

-1960. - 1970. godine - Unapređenje prodaje i marketinga, nije se dovoljno vodilo računa o finansijskom trošku zaliha, sve veće interesovanje za vrijeme isporuke, način isporuke i stepen raspoloživosti;

\section{NAPOMENA:}

Ovaj rad proistekao je iz master rada čiji mentor je bio dr Stevan Milisavljević.
- Posle 1980. godine - Značajne reserve racionalizacije, logistika postaje konkurentno oružje, proširenje na različita tržišta, porast potreba za koordinacijom i kontrolom kretanja svih materijalnih i robnih tokova [1].

Jedna od opšte prihvaćenih definicija današnjice, koja uključuje i povratnu logistiku, donjeta je od strane Vijeća Evrope, koja glasi: „Logistika predstavlja upravljanje tokovima robe i sirovina, procesima izrade, završenih proizvoda i pridruženim informacijama od tačke izvora do tačke krajnje upotrebe u skladu sa potrebama kupca. U širem smislu logistika uključuje povrat i raspolaganje otpadnim materijama [2].

Zadaci logistike su da prati, proučava, analizira i ispituje sve pojave na tržištu traženih proizvoda, u tehnološkom procesu proizvodnje, u klavitetu usluga, u transport, $\mathrm{u}$ skladištenju, u pakovanju i rukovanju proizvodima, što utiče na visinu troškova. Osnovni i najvažniji zadatak logistike jeste da kupac bude zadovoljan [3].

Cilj logistike odnosi se na povećanje efikasnosti poslovanja putem ubrzanja cirkulacije angažovanih sredstava. Ovaj cilj može se ostvariti na dva načina: skraćivanjem prosječnog vremena angažovanja (eliminisanjem prepreka koje uzrokuju zastoje unutrašnjeg transporta primjenom specifičnih metoda), i smanjivanjem prosječne sume angažovanih sredstava [4].

\section{NABAVKA}

Nabavka je proces obezbjeđivanja inputa neophodnih za nesmetano obavljanje procesa proizvodnje. Glavna pitanja nabavke su: izbor dobavljača, izbor inputa, vremenski raspored nabavki, nivo cijena, ulazna kontrola kvaliteta [5].

Upravljanje lancem snabdjevanja (Supply Chain Management) je globalna strategija u 21. vijeku za sticanje konkurentske prednosti. Stoga nabavna logistika ima važnu ulogu u snabdjevanju, njenom optimizacijom stiče se značajan efekat na cjelokupni sistem.

Proces nabavke se sastoji od predfaze, faze i postfaze. U predfazi procesa nabavke odvijaju se aktivnosti unutar kompanije, vezane za utvrđivanje potrebe za materijalima. U fazi nabavke odvijaju se aktivnosti između kompanije kupca i dobavljača. U postfazi nabavke odvijaju se aktivnosti unutar kompanije i vezane su za smještaj nabavljenih materijala.

Proces nabavke prolazi sledeće faze: identifikacija potreba za nabavkom, identifikacija dobavljača, slanje upita, prijem ponuda, razmatranje ponuda $\mathrm{i}$ izbor 
optimalne ponude, izbor dobavljača, dostavljanje naloga narudžbenica dobavljaču, unutrašnji transport i skladištenje materijala u kompaniji [6].

Efikasna nabavka podrazumjeva sedam opštih ciljeva:

$$
\begin{array}{ll}
\checkmark & \text { Odgovarajući material } \\
\checkmark & \text { U odgovarajućim količinama } \\
\checkmark & \text { U odgovarajućem stanju } \\
\checkmark & \text { U odgovarajućem vremenskom trenutku } \\
\checkmark & \text { Iz odgovarajućeg izvora } \\
\checkmark & \text { Sa odgovarajućom pratećom uslugom } \\
\checkmark & \text { Pri odgovarajućoj cijeni [7]. }
\end{array}
$$

Nakon što je sektor nabavke upoznat sa potrebama sredstava za proizvodnju prema svim karakteristikama, kao što je količina, vrsta, trenutne zalihe, itd, on dalje mora istražiti izvore snabdjevanja, te izabrati najpovoljnijeg dobavljača.

Nabavku pokriva standard ISO 9001. Menadžeri snabdjevanja moraju koristiti raznovrsne izvore kako bi odabrali domaće i međunarodne dobavljače. Preduzeće koristi sve korake u izboru dobavljača samo kada prvi put posluju sa njim ili kada se obavlja preispitivanje poslovanja snabdjevača. Kompanija - kupac prikuplja informacije o dobavljaču na različite načine.

Posle detaljne analize izbora dobavljača, menadžer snabdjevanjem optimizira početnu listu dobavljača. $\mathrm{Na}$ kratkoj listi se nalaze najbolji, ili više njih. Izabrani dobavljači biće izloženi detaljnoj analizi svojih operacija. Menadžer snabdjevanja mora ispitati dobavljačeve sposobnosti, nivo tehničke stručnosti, program osiguranja kvaliteta, poslovne zgrade koje posjeduje, stil upravljanja, sposobnost Just in Time isporuke [8].

S' obzirom da će u nastavku rada detaljnije biti prikazan process logistike nabavke u kompaniji „Hutchinson“, koja posluje u okviru automobilske industrije, treba napomenuti da nabavku u automobilskoj industriji pokriva specijalizovani standard IATF 16949, koji predstavlja dopunu gore navedenog ISO 9001.

Menadžeri snabdjevanja nabavljaju raznovrsne materijale za preduzeća. Većina nabavki se može razvrstati u sledeće kategorije:

- Dijelovi / komponente (proizvodne nabavke)

- Sirovine (proizvodne nabavke)

- Procesni materijali (neproizvodne nabavke)

- Pomoćna oprema (nabavke dijelova i usluga)

- Glavna oprema (neproizvodne nabavke)

- Operativno snabdjevanje (neproizvodne nabavke)

- Gotovi proizvodi (korporativne nabavke)

- Usluge (neproizvodne nabavke)

\section{UPRAVLJANJE LOGISTIKOM U KOMPANIJI HUTCHINSON}

Hutchinson je dio Total group. U pitanju je francuska kompanija, koja ima više od 160 godina dugu tradiciju sa operacijama u 25 zemalja širom Evrope, Azije i Amerike. Hutchinson je globalni lider u kontroli vibracija, upravljanja fluidima i zaptivanjima.

Proizvodnja u Rumi je započeta u februaru 2016. Godine. U Rumi postoje dvije divizije:

- Fuel - proizvodnja plastičnih crijeva za gorivo

- Water - proizvodnja gumenih crijeva za vodu.
Neki od kupaca kompanije su Mercedes, Fiat, Suzuki, Reno, itd. Fabrika u Rumi trenutno broji više od 1500 radnika. Kompanija Hutchinson spada u prvi nivo dobavljača, gdje se uz proizvodnju crijevi vrši i montaža komponenti, i takav konačni proizvod se šalje proizvođaču automobila.

U sektoru logistike, na samom čelu organizacione structure je Menadžer logistike, kome su dalje podređeni dva koordinatora logistike, koji rukovode timovima, samo podjeljeni na divizije Fuel i Water, i jedan Customer support koordinator.

* Upravljanje transportom:

U okviru sektora logistike, zaposlena je jedna osoba, zadužena za evidentiranje usluga transporta, kontrolu troškova transporta, saradnju sa eksternom agencijom koja vrši transport, saradnju sa sektorom finansija i računovodstva. Za Hutchinson usluge transporta robe vrši kompanija Transfera, sa sjedištem u Beogradu, ulica Savski nasip 7.

\section{* Customer support tim}

Customer support tim u kompaniji Hutchinson sastoji se od dvanaest osoba. Tim je podjeljen po projektima, svaki član tima je zadužen za jedan ili više projekata u kompaniji. U logistici, samo ovaj tim, zbog svoje brojnosti, ima svog koordinatora, kome je dalje nadređen menadžer logistike. Customer support tim se nalazi na kraju lanca logistike, ili ako ćemo tačnije, na početku tog lanca, jer Hutchinson posluje po PULL principu. Zaposleni u okviru ovog tima su u direktnoj vezi sa kupcima, i predstavljaju na neki način osobu koja kupčeve zahtjeve prezentuje kompaniji.

\section{* Pakovanje}

U kompaniji su zaposlene dvije osobe, sa nazivom pozicije Packaging specialist. Obe divizije imaju po jednog specijalistu za pakovanje. Osnovni zadatak im je nabavka kartonskih i drugih pakovanja za robu koja se otprema iz kompanije do kupca.

\section{* PDP / Pull Flow (planiranje proizvodnje)}

Termin PDP predstavlja skraćenicu sa francuskog jezika Plan de production (plan proizvodnje). Kao i kod pakovanja, po jedan planer proizvodnje je u obe divizije. Zadatak im je da na osnovu kupčevih zahtjeva, poslatih preko Customer support tima, unosi podatke $\mathrm{u}$ plan proizvodnje $\mathrm{i}$ tako na dalje pripremi podatke nabavci $\mathrm{u}$ okviru logistike.

\section{* $\quad$ Procurement (nabavka)}

Procurement čine po dva administratora u obe divizije. Osnovni cilj ovog tima se odnosi na pravovremeno snabdjevanje proizvodnje komponentama. Kao osnovni zadaci, pored korespondencije sa dobavljačima i poručivanja repromaterijala, izdvajaju se još i organizacija transporta $u$ saradnji sa Transferom, organizacija prijema robe $\mathrm{u}$ magacinu, vrjednovanje dobavljača, izrada izvještaja o stanju zaliha.

\section{* Služba skaldištenja}

Kompanija posjeduje dva skladišta, po jedan u obe divizije. Sastoje se iz dva dijela: magacin repromaterijala i magacin gotovih proizvoda. Njima rukovodi koordinator magacina. Tri osnovna zadatka su prijem i skladištenje robe, izdavanje robe u proizvodnju, otpremanje robe za slanje kupcu. 


\section{SNIMAK STANJA PROCESA LOGISTIKE NABAVKE U KOMPANIJI HUTCHINSON}

Kao što je navedeno, krajnji cilj Procurement tima odnosi se na pravovremeno snabdjevanje proizvodnje komponentama, uz što niže troškove. Sav proces zasniva se na čuvenih 7P: pravi material, u pravoj količini, pod pravim uslovima, u pravo vrijeme, iz pravih izvora, sa pravom uslugom, na pravom mjestu.

Termini koji se koriste najčešće u poslu Procurement administrator su:

- Open order - porudžbine koje se rade sistemski i šaljemo porudžbenice. Ove komponente se redovno naručuju i za njih je određena manja cijena nego inače, na osnovu odobrenja top menadžmenta obe kompanije.

- Closed order - komponente koje poručuje Project leader, u saradnji sa sektorom nabavke, a koje se poručuju u svrhu uzorkovanja za određene projekte, ili zamjenu nekih postojećih komponenti.

- Firm order - porudžbina koja je konačna i poslata dobavljaču, označava se sa slovom $\mathrm{F}$ u sistemu

- Forecast order - odnosi se na prognoze koje se šalju dobavljaču, da bi dobavljač znao u budućnosti kako da planira svoju proizvodnju, a ne predstavljaju konačne porudžbine i mogu se promjeniti. Označavaju se sa slovom $\mathrm{P}$ u sistemu

- MOQ (minimal order quantity) - odnosi se na minimalnu količinu koja se mora poručiti.

- Lead time - vrijeme od plasiranja porudžbine do preuzimanja robe. Prosjek je 7/8 sedmica.

- Transit time - vrijeme koje protekne od preuzimanja robe do prijema u magacin

- Incoterms - pariteti isporuke, koji pokazuju u čijoj je organizaciji transport.

- Backlog - odnosi se na robu koja je u kašnjenju od strane dobavljača

- Obsolate - odnosi se na robu koja je zastarjela, koja se više ne koristi.

- Pick up - termin za kupljenje robe od dobavljača

- Gemba - sastanak u proizvodnji, ili magacinu.

- Audit - kontrola koja može biti vezana za sertifikaciju, ili kupčeva kontrola

- Custom clearance - postupak carinjenja

Posao administratora nabavke počinje i zasniva se na osnovu plana proizvodnje, koji je skrojen na osnovu zahtjeva kupaca prezentovanih od strane Customer support tima. Nakon unjetog plana, administrator u utorak ujutru otvaraju Excel tabelu Checking of components, i biraju opciju Data/Refresh, kako bi Excel povukao iz sistema sve podatke o komponentama, koje su prethodno unjete $\mathrm{u}$ tabelu. $\mathrm{Na}$ taj način se vide sve potencijalne kritične komponente. Tabela sadrži oznaku komponente sa pozicijama u magacinu, pick up zoni i proizvodnji.

$\mathrm{Na}$ osnovu tabele se počinje sa kreiranjem porudžbina za dobavljače. Politika firme je da process proizvodnje treba biti pokriven stanjem zaliha zajedno sa porudžbinama oko dva mjeseca, ne više. Zbog lead time dobavljača, process zahtjeva da se porudžbenice kreiraju za svakog dobavljača sedmično, ili za neke dobavljače sa kraćim lead time može i jednom u dvije sedmice.
Teoretski, trebalo bi da softver koji se koristi, Mac Pack, sam odredi Forecast order za dalji period, a administrator samo da $\mathrm{u}$ sistemu slovo $\mathrm{P}$ zamjene sa $\mathrm{F}$ i potvrde porudžbinu. Zbog nefunkcionisanja sistema u kompaniji, softver to ne omogućuje, i predviđanje porudžbina je stvar manuelnog rada administrator, i zahtjeva dodatno vrijeme i izrazitu preciznost prilikom kalkulisanja potreba. Zbog velikih sistemskih nedostataka, standardan broj kritičnih komponenti u Excel tabeli je oko 100 komponenti. Mnoge od njih nisu kritične, nego je prikazano pogrešno stanje.

U zavisnosti od pariteta koji je dogovoren, zavisi ko vrši transport. Uglavnom se koriste samo DAP (delivery at place), i EXW(ex works). U momentu kada je roba spremna za preuzimanje, u slučaju pariteta EXW administrator dobija mejl od kontakt osobe dobavljača, da je roba spremna. Informacije koje su potrebne administrator, su informacije koje se odnose na broj paleta, dimenzije paleta, težinu robe, a od dokumentacije faktura, otpremnica (delivery note).

Sa svim ovim podacima, popunjava se formular Zahtjev za transport, koji se dalje prosleđuje osobi iz logistike zaduženoj za vođenje evidencije o transportu.

Neke od vrsta drumskog transporta koje Transfera raspolaže su:

- Zbirni transport - treba da se koristi u većini slučajeva. Najisplativiji vid transporta. Rutu transporta određuju zaposleni iz Transfere, što znači da u njihovim vozilima ima i druge robe.

- Taxi - označava manji kamion, naziva se još I solo kombi, koji se šalje u hitnim slučajevima, kada nam treba roba danas za sutra, ili u roku od 2-3 dana ako su u pitanju dobavljači kao npr. iz Španije.

- Šleper i Avia - su kamioni različitih dimenzija, sa bržim rokom stizanja nego zbirni transport.

Pored drumskog transporta, Transfera vrši i avio i brodski transport. Bitna stavka kod organizacije transporta, je i optimizacija transporta.

Usluge carinjenja takođe vrši Transfera. U momentu kada dođe roba, vrši se prijem robe, fizički i sistemski. Svakog jutra, administrator dobija tabelu sa tačnim pozicijiama vozila i na osnovu toga najavljuje prijeme u magacinu i priprema dokumentaciju.

Jedan od poslova administratora je takođe i vrjednovanje dobavljača, na osnovu ispoštovanih rokova, količina i slično. Na kraju svakog mjeseca dobavljači dobijaju izvještaj o tome kako su ocjenjeni.

Takođe, jedan od izvještaja jako bitnih menadžmentu je i izvještaj od stanju zaliha i pokrivenosti zalihama. Radi se svakog mjeseca, najdalje do 5-og u mjesecu.

\section{MJERE UNAPREĐENJA PROCESA NABAVKE REPROMATERIJALA U KOMPANIJI HUTCHINSON}

$\mathrm{Na}$ osnovu ličnog iskustva u radu, u kompaniji Hutchinson, u nastavku će biti predložene mjere za unapređenje poslovanja. Mjere će biti raspoređene po grupama, odnosno, odnosiće se na svaku grupu uzroka iz prethodno razrađenog Ishikawa dijagrama, koji je za posledicu imao Stopiranje proizvodne linije zbog nedostatka komponenti. 


\section{Menadžment:}

Saradnja sa rezervnim dobavljačima za kritične komponente - To bi podrazumjevalo sklapanje dogovora sa određenim dobavljačima koji bi se tretirali kao rezervni dobavljači, za određeni broj komponenti koje se jako često koriste, i za one koje imaju jako dug lead time.

Zapošljavanje još jedne osobe u Procurement timu Smatram da bi se time povećala produktivnost tima. Zbog mnogo nedostataka u organizaciji poslovanja, otežan je rad administratorima, te proizilazi da se zanemaruju određeni zadaci, jer redovno dolaze do izražaja riječi: prioritet, urgentno, eskalacija, itd.

\section{$>\quad$ Kašnjenje isporuke:}

Kućno carinjenje - jedan od savremenih trendova sa kojim se u mnogo slučajeva mogu izbjeći čekanja na carinskim terminalima, jeste takozvano kućno carinjenje. U pitanju je pojednostavljeni carinski postupak, izdaje se od strane Uprave carina, na obostranu korist i interes. Dobijaju ga kompanije koje imaju veće potrebe za njim, prouzrokovane stalnim uvozom i izvozom, što je slučaj u Hutchinsonu. Postupak se sprovodi tako što kada kamioni dolaze na granicu, ne moraju da idu u carinsko područje i čekaju na red. Kamioni se direktno upućuju sa granice na odredišno mjesto kupca. Zatim kamion se pozicionira $\mathrm{u}$ prostoru za carinsko područje kupca, i šalju se elektronskim putem sva potrebna dokumenta u nadležnu carinarnicu. Takođe ne bi se moralo ići do carinskih terminal i gubiti vrijeme i za to. Takođe, jako su značajne dodatne novčane uštede. Odnose se na plaćanje terminal, koje se u ovom slučaju ne bi plaćalo, kao i plaćanje administrativnih taksi za uvjerenja EUR 1.

\section{$>\quad$ Magacin:}

Zapošljavanje još jednog radnika u magacinu - Navedeno unapređenje bi podrazumjevalo zaposlenje radnika $\mathrm{u}$ magacinu koji bi imao jasno precizirane odgovornosti i zadatke. Cilj je da se navedeni radnik obuči za samo određene zadatke ispod i da mu se u skladu sa time dodijele odgovornosti: izvršavanje funkcije prijema $u$ softveru, obavještavanje Procurement tima o prispjeću robe, obavještavanje drugog magacina o prispjeću robe, ukoliko ima nešto za drugi magacin, i popunajvanje otpremnice Voter - Fjul, koja je navedena u nastavku rada, dekalrisanje robe prilikom izdavanja iz magacina u proizvodne linije.

Izdavanje otpremnice Voter - Fjul -Razlog zbog kojeg predlažem kreiranje ovakvog dokumenta, jeste da nije precizno definisana komunikacija između dva magacina $u$ divizijama Voter i Fjul. Često se dešava da određeni dobavljač dostavi robu i za diviziju Voter i za diviziju Fjul, u samo jedan od ta dva magacina. Zatim, u tom istom magacinu se zaprimi softverski roba koja je samo za tu diviziju, a ostatak robe koja je za drugu diviziju, ostaje na određenom mjestu netaknuta, i niko nije obavješten o njenom prispjeću. Svrha ove otpremnice je da spreči prazne hodove i traženje robe po magacinu. Prilikom prijema robe, ukoliko postoji roba za drugu diviziju, obavezno se popunjava predložena otpremnica i dostavlja roba u drugi magacin.

\section{$>\quad$ Softver:}

Unapređenje softverske podrške implementacijom SAP S/4 HANA - Smatram da za ovako kompleksne sisteme je neophodno implementirati ozbiljniji softver. Neki od razloga zbog kojih Mac Pack smatram zastarjelim, jesu: otežano kretanje kroz program, nepreciznost teksta $u$ programu, nepregledno konstruisane određene operacije, nemogućnost korišćenja više prozora na pozadini istovremeno, ne pruža nikakve analitičke mogućnosti, povremeno se dešava da zbog zauzetosti programa, potpuno se stopira rad i zahtjeva pokretanje programa bez čuvanja podataka, operacije se prinudno rade u Excelu. Zbog svega navedenog, predlažem implementaciju najsavremenijeg programa koji je kompanija SAP razvila, koji predstavlja čestvrtu generaciju poslovnih rješenja.

\section{ZAKLJUČAK}

Kompanije su danas uslovljene veoma visokim zahtjevima kupaca, koji se stalno mjenjaju, sa skraćenjem rokova isporuke i skraćenjem životnog ciklusa proizvoda. Troškovi logistike u preduzećima čine od 10 do $30 \%$ prodajne cijene proizvoda, pa zbog toga proizilazi mogućnost za poboljšavanje ukupnog logističkog procesa. U današnje vrijeme važi pravilo: „Ne pobjeđuje najbolje preduzeće, već najbolji lanac snabdjevanja“.

Predmet i tema ovog rada se odnosi na unapređenje nabavke repromaterijala u kompaniji Hutchinson. U prvom dijelu rada je teoretski prezentovana logistika, sa posebnim naglaskom, i opisom nabavke repromaterijala za snabdjevanje proizvodnje. U drugom dijelu rada prikazan je snimak stanja logistike nabavke u kompaniji, kao i predložene mjere unapređenja poslovanja.

\section{LITERATURA}

[1] Avlijaš G., Razvoj i pojam logistike, Sinergija, 2008.god

[2] Šamanović J., Prodaja, distribucija, logistika, Ekonomski fakultet, Split, 2012.god

[3] http://studenti.rs/skripte/logistika-preduzeca

[4] Vasiljević M., Logistika u saobraćaju, Saobraćajni fakultet u Doboju, 2011. god.

[5] Anđelić G., Strategijski menadžment, Fakultet tehničkih nauka, Novi Sad, 2009. god.

[6] Jovanović M., Petrović G., Transportni tokovi materijala i proizvoda, Mašinski fakultet, Niš, 2009

[7] Beker I., Stanivuković D., Logistika, Fakultet tehničkih nauka, Novi Sad, 2003. god.

[8] Božić V., Aćimović S., Marketing logistika, Ekonomski fakultet, Beograd, 2010. god.

\section{Kratka biografija:}

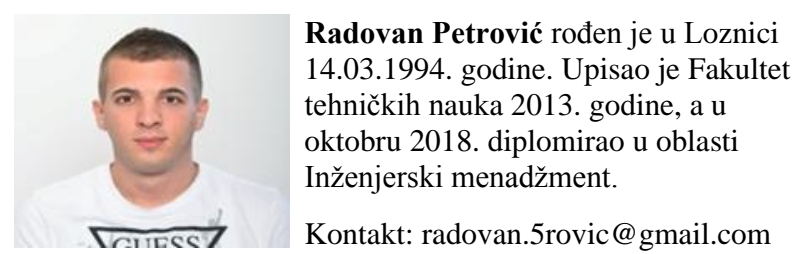

